\title{
Magnitude of Multidrug Resistance and Associated Factors of Pulmonary Tuberculosis Among Adult Smear Positive Patients in Eastern Ethiopia
}

\author{
Ziad Amin' \\ Habtamu Mitiku iD ${ }^{2}$ \\ Dadi Marami iD ${ }^{2}$ \\ Tadesse Shume (iD) ${ }^{2}$ \\ Fitsum Weldegebreal $\mathbb{D}^{2}$ \\ 'Harari Health Research and Regional \\ Laboratory, Harar, Ethiopia; ${ }^{2}$ Department \\ of Medical Laboratory Sciences, College \\ of Health and Medical Science, Haramaya \\ University, Harar, Ethiopia
}

Correspondence: Fitsum Weldegebreal Email fwmlab2000@gmail.com
Background: In Ethiopia, multidrug resistant tuberculosis is a major public health problem. However, information is scarce regarding MDR-TB and associated factors.

Objective: The study was aimed to assess the magnitude of multidrug resistance and associated factors of pulmonary tuberculosis among adult smear-positive patients in Harari regional state health facilities, eastern Ethiopia.

Methods: A cross-sectional study was conducted among 395 adult smear-positive pulmonary tuberculosis patients attending health facilities from March to October 2019. Smearpositive sputum samples were collected from health facilities, and transported to Harari Health Research and Regional Laboratory, and tested for drug susceptibility using a line probe assay. Data were analyzed using Statistical Package for Social Sciences version 20. Bivariate and multivariable logistic regression analyses with $95 \%$ confidence intervals were carried out to identify factors associated with multidrug-resistant tuberculosis.

Results: The overall magnitude of multidrug-resistant tuberculosis was 3.8\% (15/395) (95\% CI: $2.0-5.8 \%)$. Being male ( $\mathrm{AOR}=4.9 ; 95 \% \mathrm{CI}: 1.16,20.5)$, patients with a previous history of tuberculosis $(\mathrm{AOR}=4.9 ; 95 \% \mathrm{CI}: 1.5,29.6)$, treatment failure $(\mathrm{AOR}=8.5 ; 95 \% \mathrm{CI}: 1.61$, $45.3)$, treatment default $(\mathrm{AOR}=10.38 ; 95 \% \mathrm{CI}: 1.86,58.0)$, human immunodeficiency virus co-infection $(\mathrm{AOR}=9.83 .95 \% \mathrm{CI}: 3,21,30.1)$ and a previous history of contact with multidrug-resistant tuberculosis patients $(\mathrm{AOR}=14.4 ; 95 \% \mathrm{CI}: 3.1,67.6)$ had higher odds of multidrug-resistant tuberculosis.

Conclusion: The overall magnitude of multidrug-resistant tuberculosis was high. Strengthening the tuberculosis control program by giving special attention to HIV co-infected patients, treatment failure and default, previously infected patients as well as to those individuals who have a history of contact with multidrug-resistant tuberculosis infected patients .

Keywords: magnitude, multidrug resistance, pulmonary tuberculosis, eastern Ethiopia

\section{Background}

Resistance to both isonicotinic acid hydrazide (INH) and rifampicin (RIF) with or without resistance to other first-line anti-tuberculosis (TB) drugs is known as multidrug-resistant tuberculosis (MDR-TB). ${ }^{1}$ Inappropriate use of antimicrobial drugs, or use of ineffective formulations of drugs (such as the use of single drugs, poor- quality medicines or bad storage conditions), and premature treatment interruption can cause the emergence of MDR-TB. In addition, it can be aggravated by Human Immunodeficiency Virus (HIV), under-nutrition, diabetes, smoking, and alcohol consumption. ${ }^{2}$ Cases of re-treatment drug resistance is frequently detected, 
because previously treated patients can harbor strains with full or partial drug resistance. ${ }^{3}$

In 2018, out of the total TB incident cases reported, 484,000 were rifampicin resistant tuberculosis (RR-TB), and of these, $78 \%$ had MDR-TB. A total of 214,000 patients died due to MDR/RR-TB. ${ }^{4}$ Amongst all TB deaths an estimated 214,000 are due to MDR-TB. ${ }^{5}$ Even if drug-susceptible TB is reported to be reducing, MDR and extended multidrug-resistant tuberculosis (XDR-TB) are on the upsurge as a result of undiagnosed, untreated, or inappropriately treated MDR-TB cases. ${ }^{6}$

Ethiopia is one of the 30 high MDR-TB burden nations with an estimated prevalence of $2.7 \%$ and $14 \%$ among new and re-treatment cases, respectively. ${ }^{4}$ The nationwide drug resistance study estimated the rate of MDR-TB to be $1.6 \%$ in newly diagnosed TB and $11.8 \%$ among previously treated TB cases. $^{7}$

Countries having high MDR-TB are required to undergo nonstop investigation and consistent monitoring of drug resistance to determine the magnitude and distribution of drug-resistant tuberculosis. ${ }^{8}$ Nevertheless, countries like Ethiopia, have a limited capacity of laboratories to carryout culture and drug susceptibility test (DST) of M. tuberculosis. ${ }^{9}$

Anti-TB drugs has been in use for a long time in Ethiopia before the implementation of directly observed treatment short courses. ${ }^{10}$ However, information is scarce regarding MDR-TB. This study was intended to assess the magnitude of drug resistance and associated factors among adult smear-positive pulmonary tuberculosis patients in Harari regional state health facilities, eastern Ethiopia.

\section{Methods and Materials}

\section{Study Seating and Design}

This study was conducted in Harari Regional State governmental health facilities from March to October, 2019. The region is located in the eastern part of the county at a distance of $525 \mathrm{~km}$ east of Addis Ababa, the capital city of Ethiopia. According to the 2007 census, the total population of the region was $231,870 .^{11}$

The region consists of six hospitals and eight public health centers that provide TB treatments. It has also one health research and regional referral laboratory in which various diagnostic services including MDR-TB identification and DST are performed.

A cross-sectional study was conducted among adults ( $\geq 18$ years). New smear-positive pulmonary tuberculosis patients visiting TB treatment centers' during the study period were included in the study. Smear-positive pulmonary tuberculosis patients who were unable to provide appropriate sputum samples due to different reasons were excluded.

\section{Sample Size Determination and Sampling Technique}

The sample size was determined by using a single population proportion formula with the assumption of prevalence of drug resistant tuberculosis $(58.6 \%)$ from a previous study, ${ }^{12}$ with desired precision of $5 \%$, at $95 \%$ confidence interval, and $10 \%$ non-response rate. A total of 409 participants who fulfilled the inclusion criteria were recruited consecutively.

\section{Data Collection Method}

In the data collection, eight laboratory personnel were involved. Data were collected using a structured questionnaire developed after reviewing different literature ${ }^{13-16}$ and medical records were reviewed to identify participants' HIV and diabetes status. The questionnaire was initially prepared in English then translated into local languages (Amharic and Afan Oromo).

\section{Smear Microscopy}

Two consecutive spot-spot sputum specimens of at least 2$5 \mathrm{~mL}$ volume were collected in clean, leak-proof, screw cap, wide-mouth disposable containers, and examined for acid fast bacilli (AFB) in the respective health facility TB laboratory.

Smears for AFB were prepared by taking a small portion of the purulent part of the sputum with an applicator stick and smearing it on a microscope slide which was then air-dried. The standard procedure of auramine staining method was employed to confirm the presence of AFB. ${ }^{17}$ Smears were examined using light-emitting diode fluorescence microscopy (LED-FM) using 20x objective for scanning and 40x for confirmation; one length has to be scanned before reporting a smear as negative, corresponding to 300-200 high-power fields. ${ }^{17}$

All smear-positive samples for AFB were collected and transported in a cold box to the Health Research and Regional Laboratory of Harari Regional State for molecular tests by line probe assay (LPA). 


\section{Molecular Detection of Drug Resistance}

The GenoType MTBDRplus Ver 2.0 assay was performed according to the manufacturer's instructions (Germany: Hain Life Sciences). The three assay-based steps are involved in the whole procedure namely: deoxyribonucleic acid (DNA) extraction, multiplex polymerase chain reaction (PCR) amplification and reverse hybridization.

\section{DNA Extraction}

Deoxyribonucleic acid (DNA) was extracted from $500 \mu \mathrm{L}$ of the decontaminated specimen in a $1.5 \mathrm{~mL}$ microcentrifuge tube and centrifuged at $10,000 \mathrm{~g}$ for 15 minutes. The pellet was resuspended in $100 \mu \mathrm{L}$ genolyse $\mathrm{A}$ and incubated at $95{ }^{\circ} \mathrm{C}$ for 5 minutes, and then $100 \mu \mathrm{L}$ of genolyse B was added. After centrifugation, the supernatant was taken as DNA extract.

\section{Master Mix Preparation}

The master mix was prepared in a cleanroom to prevent contamination of the molecular laboratory. All the reagents needed for amplification are included in the amplification mix-A (AM-A) and amplification mix-B (AM-B) for master mix preparation. Master mixes were prepared according to the instruction. In template addition room, $5 \mu \mathrm{L}$ of DNA extracts was added to the corresponding PCR master mix tubes. For positive control, $5 \mu \mathrm{L}$ of DNA extract from $\mathrm{H} 37 \mathrm{Rv}$ quality control strain was added to the mixture, and for negative control, $5 \mu \mathrm{L}$ of sterile distilled water was used. After addition, polymerase chain reaction (PCR) was performed using pre-made amplification mixes (amplification mix-A and amplification mix-B) that contained all the necessary components. After completion of the PCR process, the amplicon was detected with a series of procedures by adding different reagents to the strip. The strips were formed color bands after the addition of the final substrate reagent. Finally, amplification and hybridization were carried out to detect the drug-resistant pattern according to the instructions. ${ }^{18}$ The master mix was prepared in master mix room by adding Mix-A (AM-A), and Mix-B (AM-B) solutions according to the manufacturer's instruction. In the template addition room, $5 \mu$ of DNA extracts was added into a 96 PCR wells containing master mix solution. For positive control, $5 \mu \mathrm{l}$ of DNA extract from H37Rv strain was added to the mixture, and for the negative control $5 \mu \mathrm{l}$ of sterile nucleic acid free water was used. After addition of the substrate, amplification, hybridization and detection of drug resistance were carried out by using line probe assay. ${ }^{19}$

\section{Data Quality Control}

Three days of training was given for data collectors on data collection procedures and data quality management. The questionnaire was pretested on $5 \%$ of TB infected patients at Haramaya District Hospital, eastern Ethiopia to check its consistency and simplicity before the actual data collection. Instruments and reagents were checked for reliability and reproducibility of the test before any test started. All new lots of reagents were tested with a known positive and negative controls.

\section{Method of Data Analysis}

The data were cleaned, coded, and double-entered using EpiData version 3.1 software and then exported to Statistical Package for Social Sciences version 20 software for analysis. Descriptive statistical tools were used to summarize the findings. Bivariate and multivariable logistic regression analyses were performed to assess the association between dependent and independent variables. Crude and adjusted odds ratio at $95 \%$ confidence interval were used to identify the predictors. Those variables with a p-value $<0.25$ at bivariate logistic regression were candidates for the multivariable logistic regression model. A p-value less than 0.05 in the multivariate analysis was used as a cutoff value to declare statistical significance.

\section{Results \\ Socio-Demographic Characteristics}

A total of 395 smear-positive pulmonary tuberculosis patients were enrolled, with a $96.6 \%$ response rate. Among them, about half of the respondents $(\mathrm{n}=203$, $51.4 \%$ ) were at the age of $26-45$ years with the mean age of 32.7 (standard deviation(SD) \pm 12.7 ) years and the majority of participants $(n=295,74.4 \%)$ were females. Most of the respondents $(n=311,78.7 \%)$ were from rural areas and $(\mathrm{n}=133,33.7 \%)$ attended secondary school (Table 1).

\section{Behavioral Characteristics of Study Participants}

Of all the participants, those who had reported a smoking habits, chewing khat, and drinking alcohol were $25.3 \%$ (100/395), 39\% (154/395), and 21.3\% (84/395), respectively. 
Table I Socio-Demographic Characteristics of Smear-Positive Pulmonary Tuberculosis Patients Who Attended Health Facilities in Harari Regional State, Eastern Ethiopia, 2020 $(\mathrm{n}=395)$

\begin{tabular}{|c|c|c|c|}
\hline \multicolumn{2}{|l|}{ Variable } & \multirow{4}{*}{$\begin{array}{l}\text { Frequency } \\
139 \\
203 \\
53\end{array}$} & \multirow{4}{*}{$\begin{array}{l}\text { Percentage (\%) } \\
35.2 \\
51.4 \\
13.4\end{array}$} \\
\hline Age & $<25$ & & \\
\hline & $26-45$ & & \\
\hline & $>46$ & & \\
\hline \multirow[t]{2}{*}{ Sex } & Male & 100 & 25.3 \\
\hline & Female & 295 & 74.7 \\
\hline \multirow[t]{2}{*}{ Residence } & Rural & 311 & 68.0 \\
\hline & Urban & 84 & 32.0 \\
\hline \multirow[t]{8}{*}{ Occupation } & Farmer & 58 & 14.7 \\
\hline & Housewife & 40 & 10.1 \\
\hline & Student & 67 & 17.0 \\
\hline & Merchant & 80 & 20.3 \\
\hline & Unemployed & 6 & 1.5 \\
\hline & Daily laborer & 45 & 11.4 \\
\hline & Government & 52 & 13.2 \\
\hline & Prisoners & 47 & 11.9 \\
\hline \multirow[t]{5}{*}{$\begin{array}{l}\text { Educational } \\
\text { status }\end{array}$} & $\begin{array}{l}\text { Unable to read and } \\
\text { Write }\end{array}$ & & 12.9 \\
\hline & Read and write & 52 & 13.2 \\
\hline & Elementary & 57 & 14.4 \\
\hline & Secondary & 133 & 33.7 \\
\hline & College and above & 102 & 25.8 \\
\hline \multirow[t]{2}{*}{ Family Size } & $\geq 5$ & 308 & 78 \\
\hline & $<5$ & 87 & 22 \\
\hline
\end{tabular}

\section{Clinical Characteristics}

Among 395 participants, 113 (28.6\%) had a previous history of anti-TB treatment but $282(71.4 \%)$ were new cases.

Table 2 Clinical Characteristics of Smear-Positive Pulmonary Tuberculosis Patients Who Attended Health Facilities in Harari Regional State, Eastern Ethiopia, 2020 ( $n=395$ )

\begin{tabular}{|c|c|c|c|}
\hline \multicolumn{2}{|l|}{ Variable } & \multirow{2}{*}{$\begin{array}{l}\text { Frequency } \\
113\end{array}$} & \multirow{2}{*}{$\begin{array}{l}\text { Percentage(\%) } \\
28.6\end{array}$} \\
\hline Previous history of TB & Yes & & \\
\hline & No & 282 & 71.4 \\
\hline History of contact with MDR & Yes & 106 & 26.8 \\
\hline TB/TB patients & No & 289 & 73.2 \\
\hline \multirow[t]{2}{*}{ HIV status } & Positive & 58 & 14.7 \\
\hline & Negative & 337 & 85.3 \\
\hline \multirow[t]{2}{*}{ Diabetic } & Yes & 30 & 7.6 \\
\hline & No & 365 & 92.4 \\
\hline \multirow[t]{4}{*}{ Treatment category } & Failure & 63 & 15.9 \\
\hline & Relapse & 26 & 6.6 \\
\hline & Default & 24 & 6.1 \\
\hline & New & 282 & 71.4 \\
\hline
\end{tabular}

One hundred and six $(26.8 \%)$ participants had a contact history with TB patients and those who were co-infected with HIV and diabetes were $58(14.7 \%)$ and 30 (7.6\%), respectively (Table 2).

\section{Magnitude of MDR TB}

The prevalence of any resistance to RMP and/or INH was $6.33 \%$ (25/395). There was no mono resistance to RMP. About $2.5 \%(10 / 395)$ of the total were resistant to INH alone. The total prevalence of MDR-TB was 3.8\% (15/ 395) (95\% CI (2.0-5.8\%)). Besides, the prevalence of MDR-TB among new and re-treated patients was 1\% (2/ $282)$ and $11.5 \%(13 / 113)$, respectively.

\section{Factors Associated with MDR TB}

In bivariate analysis; sex, residence, previous exposure to antituberculosis treatment, a contact history with MDRTB/TB patients, HIV co-infection, treatment category, diabetes status, chewing khat, alcohol consumption, and smoking were found to be significant at $\mathrm{p}<0.25$ and were considered as a candidate for multivariable logistic regression analysis.

In multivariable analysis; sex, previous history of TB treatment, treatment category of failure and defaulter, HIV co-infection, and contact history with MDR-TB/TB patient had a significant association with MDR-TB.

Being males were 4.9 times $(\mathrm{AOR}=4.9 ; 95 \% \mathrm{CI}: 1.16$, 20.51) more likely to be infected with MDR-TB than females. Patients who had a previous history of anti-TB treatment were 6.6 times $(\mathrm{AOR}=6.6 ; 95 \% \mathrm{CI}: 1.5,29.6)$ more likely to have MDR-TB compared to their counterparts. The odds of having MDR-TB in patients with a failure of treatment were 8.5 times(AOR $=8.5 ; 95 \% \mathrm{CI}: 1.61,45.3)$ and default cases were10.4 times $(\mathrm{AOR}=10.4,95 \% \mathrm{CI}$ : $1.86,58.0)$ higher compared to the new TB patients. Those participants with a history of contact with MDR-TB/TB patients were 14.4 times (AOR $=14.4 ;$ 95\% CI: 3.09-67.6) more likely to have MDR-TB compared to those who had no contact with MDR-TB/TB patients, and HIV co-infected patients were 9.8 times $(\mathrm{AOR}=9.8,95 \% \mathrm{CI}$ : $3.21,30.1$ ) more likely to develop MDR-TB compared to their counterparts (Table 3).

\section{Discussion}

In this study, the overall prevalence of MDR-TB was $3.8 \%$. The prevalence of MDR-TB among new and retreated patients was $1 \%$ and $6.5 \%$, respectively. Males, 
Table 3 Bivariate and Multivariable Analysis Among Smear-Positive Pulmonary Tuberculosis Patients Who Attended Health Facilities in Harari Regional State, Eastern Ethiopia, 2020

\begin{tabular}{|c|c|c|c|c|c|c|}
\hline \multirow[t]{2}{*}{ Characteristics } & \multirow[t]{2}{*}{ Category } & \multicolumn{2}{|c|}{ MDR-TB } & \multirow[t]{2}{*}{ COR $95 \% \mathrm{Cl}$} & \multirow[t]{2}{*}{ AOR 95\% Cl } & \multirow[t]{2}{*}{ P-value } \\
\hline & & Yes & No & & & \\
\hline \multirow[t]{3}{*}{ Age } & $<25$ & $4(2.9 \%)$ & $135(97.1 \%)$ & $0.356(0.08, I .5 I)$ & $1.0(0.12,8.64)$ & 0.85 \\
\hline & $26-45$ & $6(2.9 \%)$ & 197 (97.1\%) & $0.79(0.22,2.79)$ & I.8 $(0.25,13.54)$ & 0.54 \\
\hline & $>46$ & $5(9.4 \%)$ & $48(90.6 \%)$ & I & I & \\
\hline \multirow[t]{2}{*}{ Sex } & Male & $10(10.0 \%)$ & 90 (90.0\%) & $6.10(2.012,18.52)^{*}$ & $4.9(1.16,20.5 \mathrm{I})^{* *}$ & 0.03 \\
\hline & Female & $5(1.7 \%)$ & $290(98.3 \%)$ & I & 1 & \\
\hline \multirow[t]{2}{*}{ Residence } & Rural & 9 (2.9\%) & $302(97.1 \%)$ & $1.59(0.429,5.91)$ & $1.25(0.174,8.98)$ & 0.83 \\
\hline & Urban & $6(7.1 \%)$ & 78 (92.9\%) & I & 1 & \\
\hline Previous History TB & Yes & $10(5.2 \%)$ & 103 (91.2\%) & $6.57(\mathrm{I} .46,29.5 \mathrm{I})^{*}$ & $6.6(1.5,29.6)^{* *}$ & 0.01 \\
\hline $\mathrm{Rx}$ & No & $5(2.6 \%)$ & 277 (98.2\%) & I & I & \\
\hline \multirow[t]{4}{*}{ Treatment Category } & Failure & $6(9.5 \%)$ & 57 (90.5\%) & $10.16(1.99,51.71)^{*}$ & $8.5(1.61,45.32)^{* *}$ & 0.03 \\
\hline & Relapse & $2(7.7 \%)$ & 24 (92.3\%) & I.48 (0.373,5.22) & $2.6(0.35,19.67)$ & 0.29 \\
\hline & Default & $5(8.8 \%)$ & 19 (79.2\%) & $2.702(0.648, \mid \mathrm{I} .26)$ & $10.4(1.86,58.0 \mathrm{I})^{* *}$ & 0.01 \\
\hline & New & 2 (0.7I\%) & 280 (99.3\%) & I & I & \\
\hline Contact history with & Yes & $12(11.3 \%)$ & 94 (88.7\%) & $15.17(3.65,62.20)^{*}$ & I4.4 (3.085,67.6)** & 0.001 \\
\hline MDR TB/TB Patients & No & $3(1.0 \%)$ & $286(99.0 \%)$ & I & 1 & \\
\hline \multirow[t]{2}{*}{ HIV Status } & Positive & 9 (I5.5\%) & 49 (84.5\%) & $9.7(2.87,33.01)^{*}$ & $9.83(3.21,30.13)^{* *}$ & 0.01 \\
\hline & Negative & $6(1.8 \%)$ & 331 (98.2\%) & 1 & 1 & \\
\hline \multirow[t]{2}{*}{ Diabetic status } & Yes & $5(16.6 \%)$ & 25 (83.4\%) & $1.93(0.42,9.0)$ & $6.9(0.81,57.96)$ & 0.77 \\
\hline & No & $10(2.8 \%)$ & 355 (97.2\%) & I & 1 & \\
\hline \multirow[t]{2}{*}{ Smoking habit } & Yes & $6(6 \%)$ & 94 (96\%) & $2.28(0.703,5.85)$ & $0.9(0.10,8.08)$ & 0.91 \\
\hline & No & $9(3.1 \%)$ & $286(96.9 \%)$ & I & 1 & \\
\hline \multirow[t]{2}{*}{ Chew khat } & Yes & $5(3.2 \%)$ & 149 (96.8\%) & $0.98(0.33,2.78)$ & $2.6(0.39,17.17)$ & 0.34 \\
\hline & No & $10(4.1 \%)$ & 231 (95.9\%) & I & I & \\
\hline \multirow[t]{2}{*}{ Drinking alcohol } & Yes & $\mathrm{I}(\mathrm{I} .2 \%)$ & $83(98.8 \%)$ & $3.19(0.5,30.2)$ & $0.26(0033,1.97)$ & 0.19 \\
\hline & No & 14 (4.5\%) & 297 (95.5\%) & I & 1 & \\
\hline
\end{tabular}

Notes: *COR at P-value $<0.05$. **AOR at P-value $<0.05$.

having previous history of $\mathrm{TB}$, treatment category of $\mathrm{TB}$ (failure and defaulter), HIV co-infected, and history of contact with MDR TB/TB patients were predictors of MDR-TB.

In the current study, the magnitude of MDR-TB was $3.8 \%$ (95\% CI: $2.0 \%, 5.8 \%)$. This finding is consistent with previous reports from Armachiho and Metema, Ethiopia (5.6\%). ${ }^{14}$ However, higher rates of MDR-TB have been reported elsewhere in Ethiopia: Jigjiga $(10.2 \%),{ }^{20}$ Amhara regional state $(6.5 \%),{ }^{21}$ and Amhara regional state $(18.2 \%) .{ }^{22}$ The variation between the studies might be explained by the difference in sample size, variation in the study population, access to health care facilities, and discrepancy in effectiveness of TB control programs.
In the present study, the magnitude of MDR TB among new cases was $1 \%$ (95\% at CI: $0.85-2 \%)$, which is consistent with other studies in eastern Ethiopia $(1.1 \%),{ }^{23}$ Amhara regional state, Ethiopia (1.8\%), ${ }^{21}$ and Zimbabwe $(2 \%) .{ }^{24}$ While, it is lower when compared to the previous study conducted in Jigjiga, Ethiopia $(4.5 \%)^{20}$ and Armanchiho and Metema district (2.3\%). ${ }^{14}$ This variation between the studies might be explained by the difference in sample size, study population, access to health care facilities, and effectiveness of TB control programs.

The magnitude of MDR-TB observed in this study among formerly treated cases was $11.5 \%$ (95\% CI: $8.8-$ 16.8). This result is in line with the study conducted in Zimbabwe (6.4\%). ${ }^{24}$ However, this finding is lower than 
the study conducted in other parts of Ethiopia: Jigjiga $(22.6 \%),{ }^{20}$ eastern Amhara region $(18.5 \%),{ }^{21}$ and Armanchiho and Metema district (13.9\%). ${ }^{14}$ This variation might be explained by the difference in sample size, study population, access to health care facilities, and effectiveness of TB control programs.

In the current finding, $100 \%$ of RIF resistance was also found to be resistant to INH, which suggests RIF's resistance might be considered as a surrogate marker for checking MDR-TB.

Males have a higher rate of MDR-TB than females. As a result, being male was significantly associated with MDR-TB. A similar conclusion was reached in Europe ${ }^{25}$ and Addis Ababa. ${ }^{15}$ The possible reason might be due to higher occupational exposure of males to the infected environment, smoking, and alcoholism.

In this current study, a previous history of TB infection was an important determinant to the development of MDR-TB. A similar pattern of results is obtained in the study conducted in other parts of Ethiopia; the eastern Amhara region, ${ }^{21}$ West Armanchiho and Metema district. ${ }^{14}$ This high risk of acquisition of MDR among previously-treated cases might be due to naturally occurred mutated resistance in the mycobacterium and inadequate or interrupted treatment with anti-tuberculosis agents.

In this study, patients with a history of treatment failure and default were associated with the occurrence of MDRTB. Similar findings are reported from Jimma, Ethiopia, ${ }^{12}$ and Amhara regional state. ${ }^{26}$ The association between TB treatment failure and MDR-TB might be related to lack of supervision of treatment, improper drug regimens, and inadequate or irregular drug supply that may have a potentiate role in drug resistance. ${ }^{13,27}$

Previous contact history with MDR-TB/TB patients was also identified as an aggravated factor for MDR-TB. This finding is comparable with the previous study reported from Jigjiga, Ethiopia. ${ }^{20}$ Several other studies have also shown this finding, that contact with a known TB patient is linked with MDR-TB due to exposure to resistant TB. ${ }^{13,27,28}$ In addition, either the transmission of MDR strains or the selection of single-drug-resistant strains may also contribute to the occurrence of MDR-TB. ${ }^{27}$

In the current study, HIV co-infected TB patients were more at risk of developing MDR-TB. Other previous studies conducted in eastern Ethiopia, ${ }^{23}$ East Shoa, Ethiopia, ${ }^{16}$ and Nigeria ${ }^{29}$ were broadly in line with this finding.
In this study, khat chewing was not associated with MDR-TB. This finding is supported by the study conducted in Oromia Region, Ethiopia which reported that chewing khat was not a forecaster of MDR-TB. ${ }^{30}$

This finding highlights that drinking alcohol and a smoking habit were not associated with MDR-TB. Whereas, the association of drinking alcohol with MDRTB was identified in studies conducted elsewhere in Ethiopia; Bishoftu Hospital ${ }^{16}$ and Amhara National Regional State. ${ }^{26}$ Similarly, the association of a smoking habit with MDR-TB was established in studies conducted in Dessie and Debre Birhan towns, Ethiopia ${ }^{31}$ and Varanasi, India. ${ }^{32}$ This difference might be due to variation in sample size, study population, access to health care facilities, and effectiveness of TB control programs.

\section{Limitation of the Study}

The limitation of the study was related to the study design nature, which is the cross-sectional nature of the study does not confirm a definitive cause and effect relationship. Drug resistance based on routine DST is important to determine the magnitude and trends of anti-TB drug resistance. Nevertheless, DST was not performed in this study.

\section{Conclusions}

The overall magnitude of MDR-TB was 3.8\% and the prevalence of MDR-TB among new and re-treated patients was $1 \%$ and $11.5 \%$, respectively. Being male, HIV co-infected, patients in treatment category failure and default, history of TB infection, and a contact history with MDR TB/TB patients were aggravating factors in the development of MDR-TB. Strengthening the TB control program by giving special focus to the HIV co-infection patients, treatment failure and default, had a previous history of TB infection, and a history of contact with MDR-TB/TB patients may help to alleviate the transmission of MDR-TB.

\section{Ethical Approval}

Ethical approval for this study was obtained from the Institutional Health Research Ethics Review Committee of the College of Health and Medical Sciences, Haramaya University. Besides, a permission letter was obtained from health institution officers. Moreover, respondents were fully informed about the purpose of the study and signed their consent. Information obtained during the study was kept confidential. This study was conducted in accordance with the Declaration of Helsinki. 


\section{Acknowledgments}

We acknowledge Haramaya University Colleges of Health and Medical Sciences Institutional Health Research Ethical Review Committee for giving the ethical clearance. Our gratitude also go to the study participants and all individuals who have contributed to the completion of this research.

\section{Author Contributions}

All authors made a significant contribution to the work reported, whether that is in the conception, study design, execution, acquisition of data, analysis and interpretation, or in all these areas; took part in drafting, revising or critically reviewing the article; gave final approval of the version to be published; have agreed on the journal to which the article has been submitted; and agree to be accountable for all aspects of the work.

\section{Funding}

The fund for this study was obtained from Harari regional laboratory and research center.

\section{Disclosure}

The author(s) declared no potential conflicts of interest concerning the research, authorship, and/or publication of this article.

\section{References}

1. World Health Organization. Multidrug and extensively drug-resistant TB (M/XDR): 2010 global report on surveillance and response. Geneva; 2010

2. World Health Organization. World Health Organization, report. Global tuberculosis report 2017. Geneva, Switzerland: World Health Organization; 2017.

3. Mak A, Thomas A, DelGranado M, Zaleskis R, Mouzafarova N, Menzies D. Influence of multidrug resistance on tuberculosis treatment outcomes with standardized regimens. Am J Respir Crit Care Med. 2008;178(3):306-312. doi:10.1164/rccm.200802-240OC

4. World Health Organization. World Health Organization, report. Global tuberculosis report 2019. Geneva, Switzerland: World Health Organization; 2019.

5. World Health Organization. World Health Organization, report. Global tuberculosis report 2018. Geneva, Switzerland: World Health Organization; 2018.

6. Muller B, Streicher E, Chihota V, Pillay M, Klopper M, Coetzee G. Programmatically selected multidrug-res istant strains drive the emergence of extensively drug-resistant tuberculosis in South Africa. PLoS One. 2013;8(8):e70919. doi:10.1371/journal.pone.0070919

7. World Health Organization. World Health Organization, global tubelosis report. Geneva, Switzerland: Worled Health Organization; 2014. Available from: www.who.int/about/licensing/copyright form/en/ index.html. Accessed October 2, 2021.

8. World Health Organization. World Health Organization, Report. Global tuberculosis report 2013. Geneva, Switzerland: World Health Organization; 2013.
9. Kebede AH, Alebachew Z, Tsegaye F, Fmo H; Federal Minstry of Health. The first population-based national tuberculosis prevalence survey in Ethiopia, 2010-2011. Int J Tuberc Lung Dis. 2014;18 (16):635-639. doi:10.5588/ijtld.13.0417

10. Mitike G, Kebede D, Yeneneh H. Prevalence of antituberculosis drug resistance in Harar Tuberculosis Centre, Ethiopia. East Afr Med J. 1997;74(3):158-161.

11. CSA. Population census of Ethiopia. Central Statistic Authority; 2007.

12. Abdella K, Abdissa K, Kebede W, Abebe G. Drug resistance patterns of Mycobacterium tuberculosis complex and associated factors among retreatment cases around Jimma, Southwest Ethiopia. BMC Public Health. 2015;15:599. doi:10.1186/s12889-015-1955-3

13. Ahmad AM, Akhtar S, Hasan R, Khan JA. Risk factors for multidrug-resistant tuberculosis in urban Pakistan: a multicenter case control study. Int J Mycobacteriol. 2012;1(3):137-142. doi:10.1016/j. ijmyco.2012.07.007

14. Mekonnen F, Tessema B, Moges F, et al. Multidrug resistant tuberculosis: prevalence and risk factors in districts of metema and west armachiho, Northwest Ethiopia. BMC Infect Dis. 2015;15(1):461.

15. Fikadu T. Risk factors for multi-drug resistant tuberculosis in Addis Ababa, Ethiopia. Univ J Public Health. 2015;3(2):1-6.

16. Desissa F, Workineh T, Beyene T. Risk factors for the occurrence of multidrug-resistant tuberculosis among patients undergoing multidrug-resistant tuberculosis treatment in East Shoa, Ethiopia. BMC Public Health. 2018;18(1):422. doi:10.1186/s12889-0185371-3

17. World Health Organization. Fluorescent light-emitting diode (LED) microscopy for diagnosis of tuberculosis; 2010.

18. World Health Organization. Molecular line probe assay for rapid screening of patients at risk of multidrug resistant tuberculosis (MDR-TB); 2008.

19. World Healt Organization. Definitions and reporting framework for tuberculosis-2013 revision; 2013.

20. Brhane M, Kebede A, Petros Y. Molecular detection of multidrug-resistant tuberculosis among smear- positive pulmonary tuberculosis patients in Jigjiga town, Ethiopia. Infect Drug Resist. 2017;10:75-83. doi:10.2147/IDR.S127903

21. Ahmed E, Ibrahim A, Mulualem A, Mengistu E, Muluwork G, Zelalem Y. Drug resistance pattern of mycobacterium tuberculosis in Eastern Amhara Regional State, Ethiopia. Microb Biochem Technol. 2014;6:2.

22. Nigus DM, Lingerew WM, Beyene BA, et al. Prevalence of multi drug resistant tuberculosis among presumptive multi drug resistant tuberculosis cases in Amhara National Regional State, Ethiopia. $J$ Mycobac Dis. 2014;4:152. doi:10.4172/21611068.1000152

23. Seyoum B, Demissie M, Worku A, Bekele S, Aseffa A. Prevalence and drug resistance patterns of mycobacterium tuberculosis among new smear positive pulmonary tuberculosis patients in Eastern Ethiopia. Hindawi Publ Corporation Tuberculosis Res Treat. 2014;2014:1-7. doi:10.1155/2014/753492

24. Timirea C, Metcalfe JZ, Chirenda J, et al. Prevalence of drugresistanttuberculosisinZimbabwe:Ahealthfacility-basedcross-sectionalsurvey. Int $J$ Infect Dis. 2019;87:119-125.

25. Faustini A, Hall J, Peruci C. Risk factors for multi drug tuberculosis in Europe: systematic review. BMJ. 2005;61(2):158-163.

26. Wondemagegn M, Daniel M, Mulat Y, Aschalew A, Bayeh A. Risk factors for multidrug resistant tuberculosis patients in Amhara National Regional State. Afr Health Sci. 2015;15:368-377.

27. Flora MS, Amin MN, Karim MR, Afroz S, Islam S, Alam M. Risk factors of multi-drug- resistant tuberculosis in Bangladeshi population: a case control study. Bangladesh Med Res Counc Bull. 2013;39:34-41. doi:10.3329/bmrcb.v39i1.15808

28. Rahman MA, Hussain MW, Alam F, Jahan MS. Multi-drug resistant tuberculosis: experience in Bogra. $J$ Teachers Assoc. 2005;18 (1):3-6. 
29. Oluwaseun E, Akinniyi P, Afolabi O. Primary multi-drug resistant tuberculosis among HIV seropositive and seronegative patients in Abeokuta, Southwestern Nigieria. Am J Res Commun. 2013;1 (10):224-237.

30. Mulisa G, Workneh T, Hordofa N, Suaudi M, Abebe G, Jarso G. Multi- drug resistant Mycobacterium tuberculosis and associated risk factors in the Oromia region of Ethiopia. Int $J$ Infect Dis. 2015;39:57-61. doi:10.1016/j.ijid.2015.08.013
31. Semunigus T, Tessema B, Eshetie S, et al. Smear positive pulmonary tuberculosis and associated factors among homeless individuals in Dessie and Debre Birhan towns, Northeast Ethiopia. Ann Clin Microbiol Antimicrob. 2016;15:50. doi:10.1186/s12941-016-0165-x.

32. Sinha P, Srivastava GN, Gupta A, Anupurba S. Association of risk factors and drug resistance pattern in tuberculosis patients in north India. J Global Infect Dis. 2017;9:139.

\section{Publish your work in this journal}

Infection and Drug Resistance is an international, peer-reviewed openaccess journal that focuses on the optimal treatment of infection (bacterial, fungal and viral) and the development and institution of preventive strategies to minimize the development and spread of resistance. The journal is specifically concerned with the epidemiology of antibiotic resistance and the mechanisms of resistance development and diffusion in both hospitals and the community. The manuscript management system is completely online and includes a very quick and fair peerreview system, which is all easy to use. Visit http://www.dovepress.com/ testimonials.php to read real quotes from published authors. 